\title{
Mapping online the environmental impact of mining operations in New Brunswick
}

\author{
D. Mioc ${ }^{1}$, F. Anton ${ }^{1}$ \& A. Ahmad ${ }^{2}$ \\ ${ }^{1}$ National Space Institute, Technical University of Denmark, Denmark \\ ${ }^{2}$ Department of Geodesy and Geomatics Engineering, \\ University of New Brunswick, Canada
}

\begin{abstract}
In this paper the methods for data processing and online mapping of the pollution with heavy metals caused by mining in New Brunswick, Canada will be presented. The mining in New Brunswick is mostly done in uninhabited areas so it does not affect the population living in the cities.

However, the remote communities of First Nations often find that the mining activities affect their sources of water and food, especially wild game.

In this project funded by Health Canada the research was done to investigate the sources of the pollution related to the mining activities and to develop mapping techniques that will allow evaluation of the risk of the pollution to the remote communities.
\end{abstract}

Keywords: mining, tailing ponds, environmental pollution.

\section{Introduction}

In Canada, mining is one of primary industries and involves the extraction, refining, and processing of economically valuable rocks and minerals, where the most important mineral products are diamonds, gold, silver iron copper zinc and nickel [1].

Before the British and French colonies were established in Canada the Aboriginal use and trade of Canada's rich mineral resources included copper, gold, silver and chert [1]. European exploration and colonization of northern North America was partially motivated by the search and exploitations of valuable minerals [1]. 
Mining has been important factor to Canadian settlement and development, but in the recent decades the industry has also been criticized for its environmental and social impacts in Canada and internationally [1]. The example is the major disaster that occurred in 2014 in British Columbia in the Cariboo region, that began in August 2014 with a breach of the copper and gold mine tailings pond owned by Imperial Metals (see Figure 1). The water and slurry of mining waste (accumulated during many years of mining) was released into Polley Lake [2]. The spill then flooded Polley Lake, its outflow Hazeltine Creek, and continued into nearby Quesnel Lake and Cariboo Creek [2].

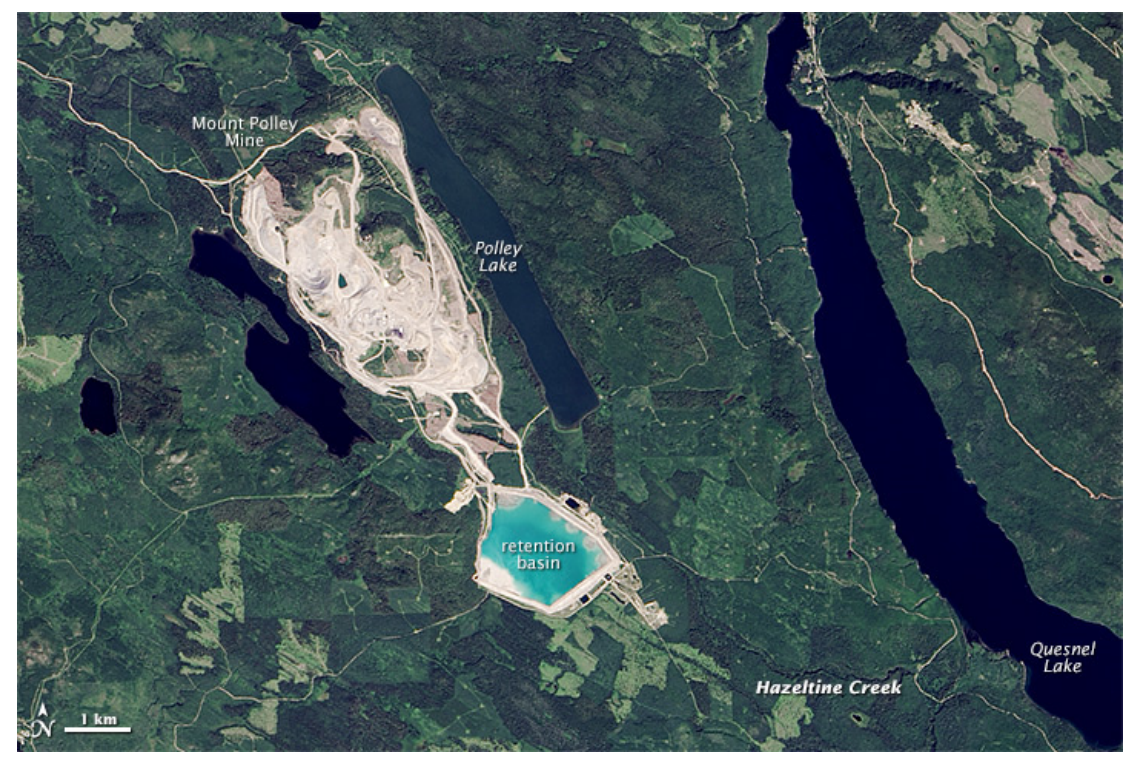

Figure 1: Tailing pond of Mount Polley mine.

http://en.wikipedia.org/wiki/File:Mount_Polley_Mine_site.jpg.

The extent of the damage is difficult to determine and it will have long-term consequences, as toxicants slowly accumulate in the environment from grass, moose to aboriginal person [2].

\section{Mining in New Brunswick}

Mining was traditionally of great importance in New Brunswick and the major minerals mined are zinc, silver and lead. Among non-metallic minerals, peat, stone and sulfur are of greatest importance [3].

Mineral extraction ranges from using basic low-technology techniques to massive energy-and capital-intensive undertakings [1]. The mining industry throughout the $20^{\text {th }}$ century developed the technologies such as underground railcars, machine hoists, and large power shovels reduced the need for human labour $[1,3]$. 
After the Second World War, declining ore grades and availability of the new technologies and machinery, allowed the development of opencast mining [3]. Opencast mining, also known as strip mining or open-pit mining, remove surface material, to reveal extensive, low-grade deposits [3]. The removal of vegetation and soils and the creation of massive pits by opencast mining are considered as a source of landscape degradation and environmental pollution [3].

Typically, the minerals form a small fraction of mined rock. Today's mining techniques often exploit ores containing a fraction of a percent of valuable minerals and they are still rentable. Mineral processing, removes target minerals through various thermo-mechanical or chemical techniques. The waste material, pulverized rock slurry known as tailings, poses a major disposal challenge and cause environmental problems [3].

Mining waste often contains heavy metals (cadmium, arsenic, lead, etc.) that occur naturally in the geological formations, but it may be released into waterways, soil, and the air (as dust) at levels that threaten the health of humans and wildlife. Moreover, tailings from sulfide mineral deposits may react with water and air to produce sulfuric acid. This acid can have chemical reaction in the environment that can dissolve more toxic heavy metals from surrounding rock or waste piles. In the case of uranium or radium mining and processing, leftover sludge contains a high amount of radioactive material. This radioactive material within tailings may present a danger to local populations of humans and wildlife [3].

\section{Mapping the potential pollution from the mining activities in New Brunswick}

Our research objective was to map the contaminants (their spatial location) affecting the general population and the First Nations in New Brunswick (see Figure 2) within an online accessible GIS. The internet accessible mapping and spatial analysis of the contamination affecting the wild game and edible plants will allow First Nations and general population in New Brunswick (for the first time) to access the information about contaminated sites and avoid their traditional activities in contaminated areas.

The contamination has been detected in the areas of New Brunswick mines and abandoned tailing ponds located nearby [7].

The mining in New Brunswick is mostly done in inhabited areas so it does not affect the population living in the cities.

However, the remote communities of First Nations often find that the mining activities affect their sources of water and food, especially wild game. According to the Indian Register System from Aboriginal Affairs and Northern Development Canada (AANDC), as of December 31, 2011, there were approximately 13,948 First Nations people in New Brunswick, 8,931 on reserve and 5,017 off reserve.

In this project funded by Health Canada the research was done to investigate the sources of the pollution related to the mining activities and to develop mapping techniques that will allow evaluation of the pollution risk to the remote communities. 


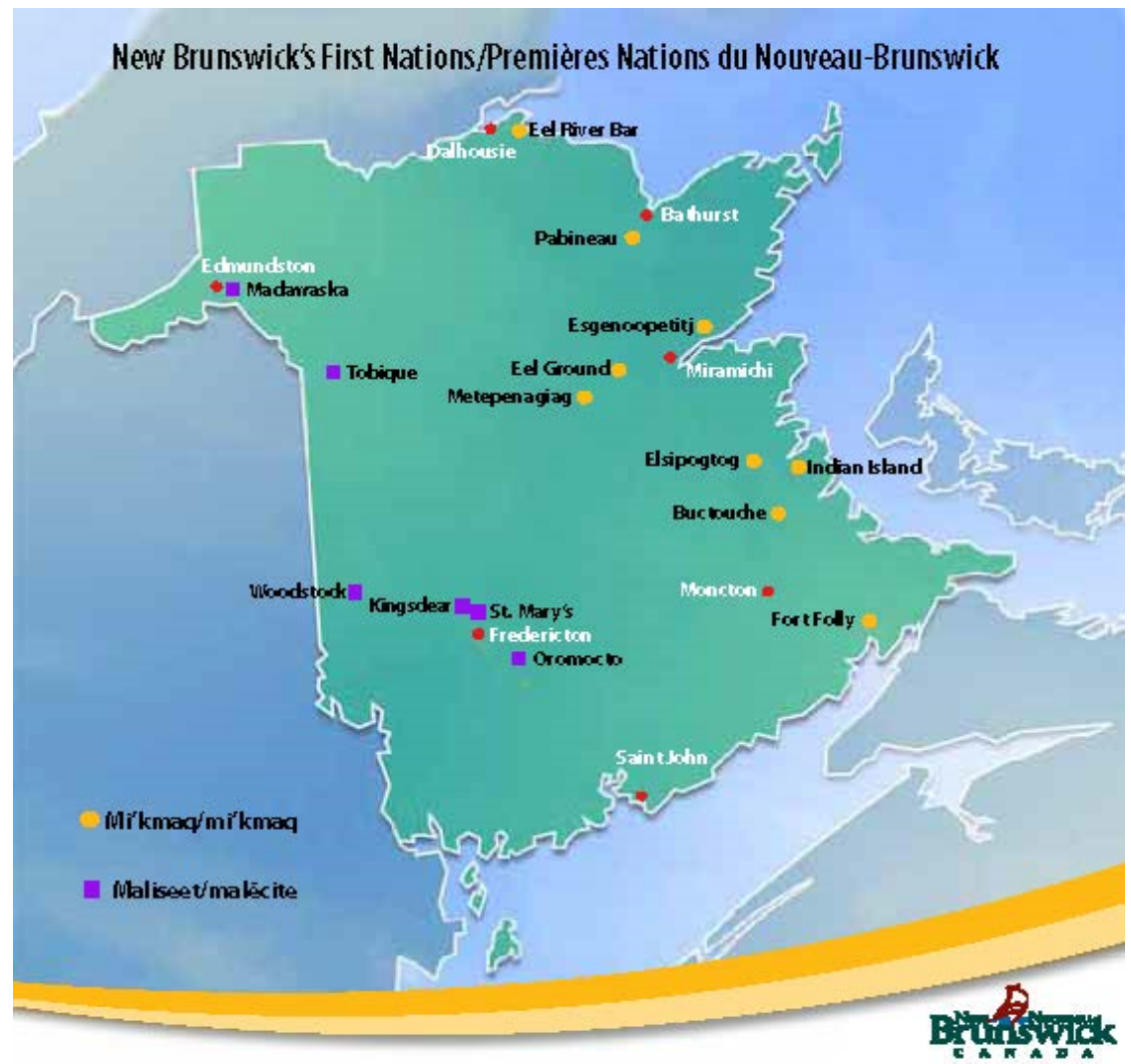

Figure 2: First Nations reserves in New Brunswick. http:/www2.gnb.ca/ content/dam/gnb/Departments/aas-saa/images/maps/First-Nationsnewbrunswick.jpg.

The recent example of the pollution risk is the Cassidy Lake Mine where PotashCorp has revealed a number of leaks have been found in a liner beneath a salt-water tailings pond at the former Cassidy Lake mine site, near Norton (see Figure 3).

The Cassidy Lake mine stopped operation in 1997 when it flooded. A 70-acre tailings pile and brine pond with a liner underneath remained. That liner, which dates from the 1980s, has been compromised, allowing brine that is essentially salt water to drain into the ground beneath [4].

According to the PotashCorp communications, the leaking salt water from the tailings pile will have to be managed for several decades [4].

The leaks, first detected in 2008, have been patched, but there could be others that haven't yet been found. PotashCorp is working with a consultant and has drilled additional wells on the mine property to capture water moving underground. The water is then pumped back into the brine pond and eventually sent by pipeline 34 kilometres to the Bay of Fundy [4]. 


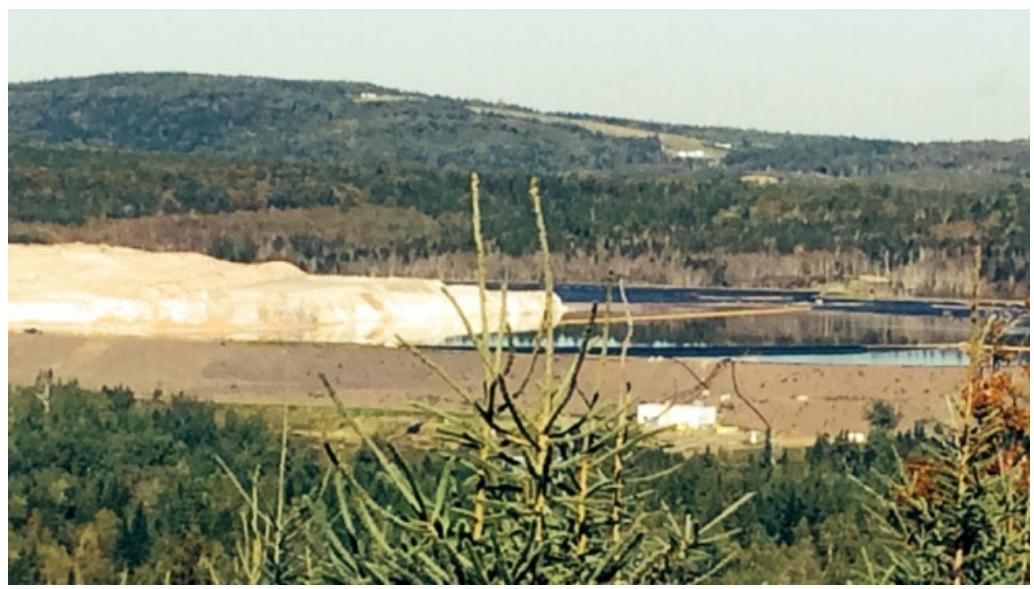

Figure 3: Cassidy Lake Mine, from [4].

The novelty in this project is to map previous findings about contaminants (their spatial location) affecting the First Nations within the web based Geographic Information System $[5,6]$. The internet accessible mapping and spatial analysis of the contamination affecting the First Nations wild game and edible plants will allow First Nations (for the first time) to access the information about contaminated sites and avoid their traditional activities in contaminated areas (see Figures 4 and 5).

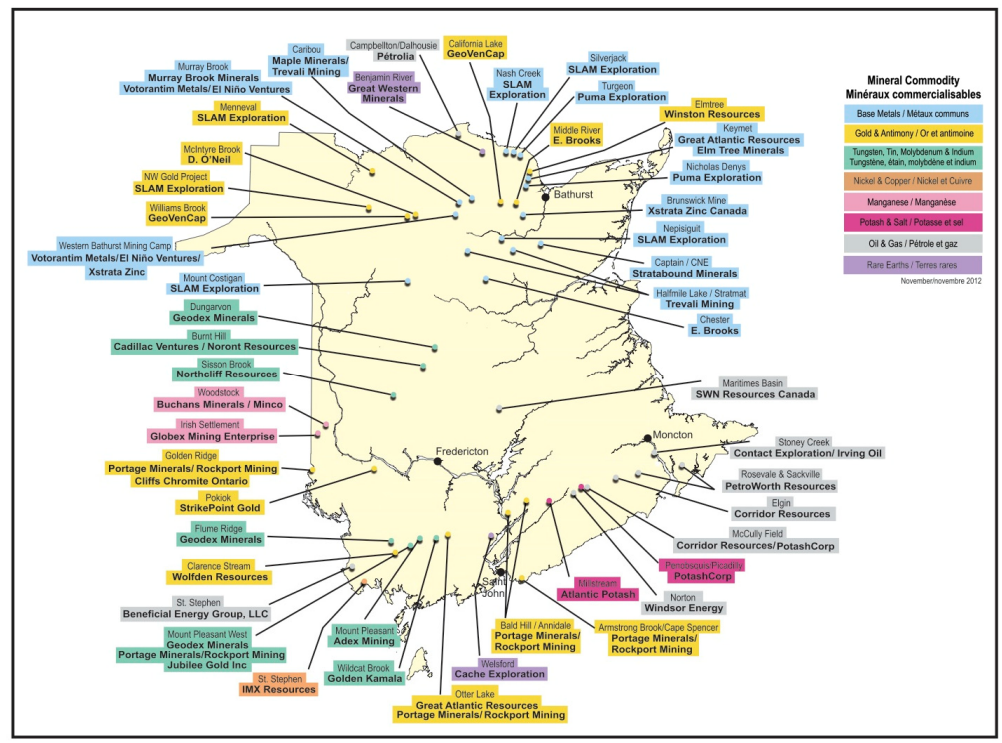

Figure 4: Mines in New Brunswick. http://images.frompo.com/ f00263a042e70ef2d17a05calf06ded3. 


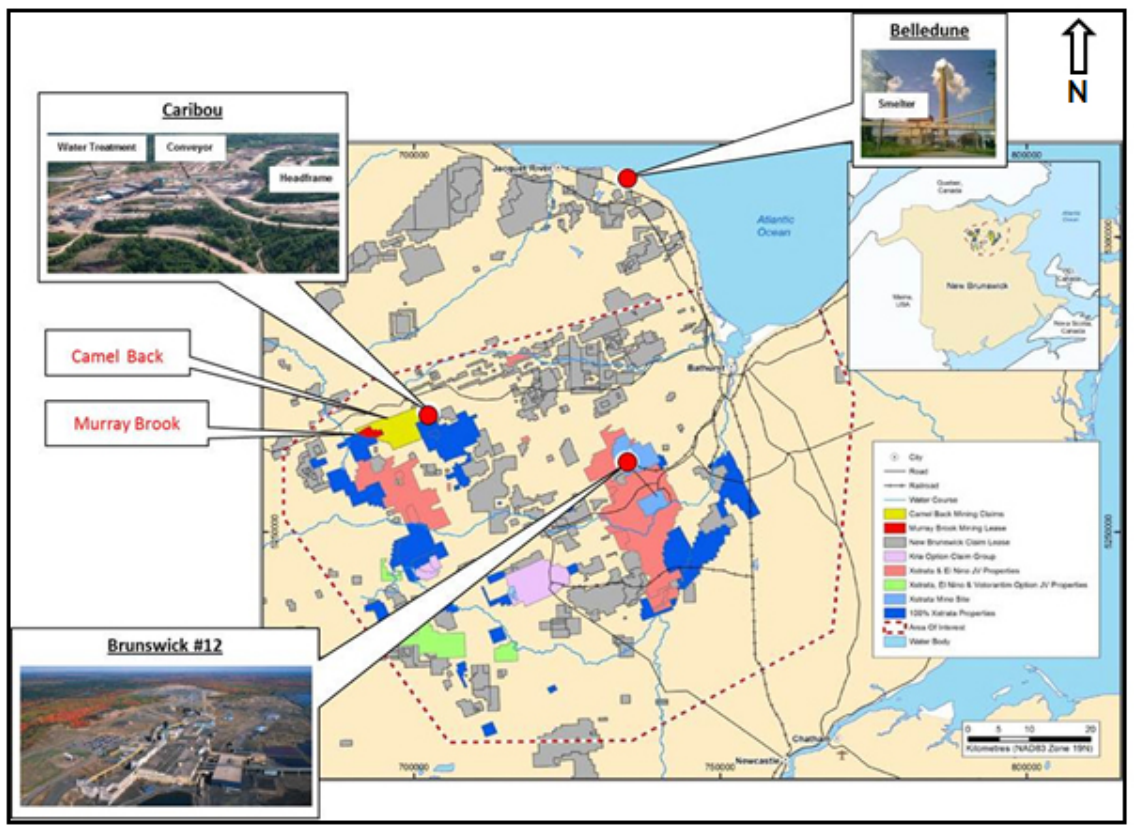

Figure 5: Detailed map and the photos of the mines near Belledune smelter, http://www.elninoventures.com/s/NewsReleases.asp?ReportID=553 466.

For this project we used around 14,000 samples available from Department of Natural Resources, New Brunswick to produce detailed geochemical maps of New Brunswick and to identify contaminated areas that affect traditional aboriginal use of the land [5].

We then combined the results of geochemical maps with the additional GIS layers (First Nations reserves, hydrographic and road networks) for advanced spatial analyses.

We also used Google Earth for integration of spatial data with existing background imagery and spatial data (cities, rivers, place names, terrain, etc.) as it can provide enhanced visualization of the tailing ponds and open pit mines.

Data about potential contamination sites were obtained from the Geological Survey of New Brunswick and included in the available GIS layers [8].

Data processing started with representing the contamination in all of the area of the province of New Brunswick, and then the comparison between the areas where the mines located and the rest of the province can be done (see Figures 6 and 7).

The processed data sets were uploaded to the Web GIS application, which can be queried interactively. For example, if the user wants to select all the mines where the copper is being exploited, and enter the query, all of the mines that have the copper "Cu" as a one of its elements being exploited, will be shown as yellow dots on the map [8]. 


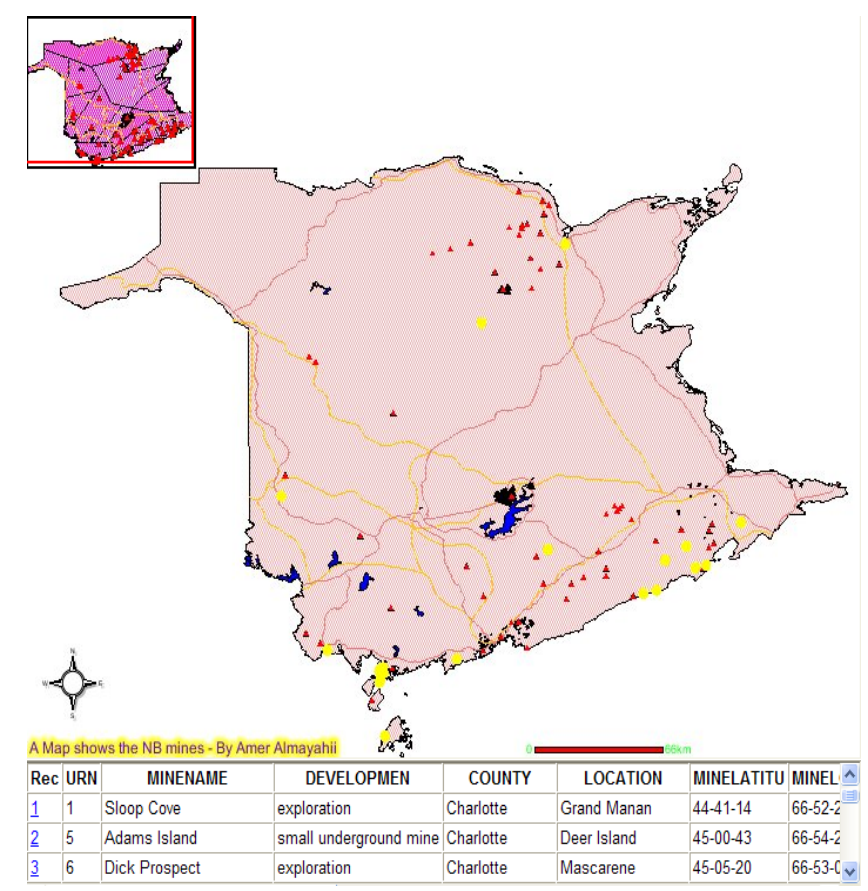

Figure 6: The Web-GIS application for interactive query and display of mining activities in New Brunswick, from [8].

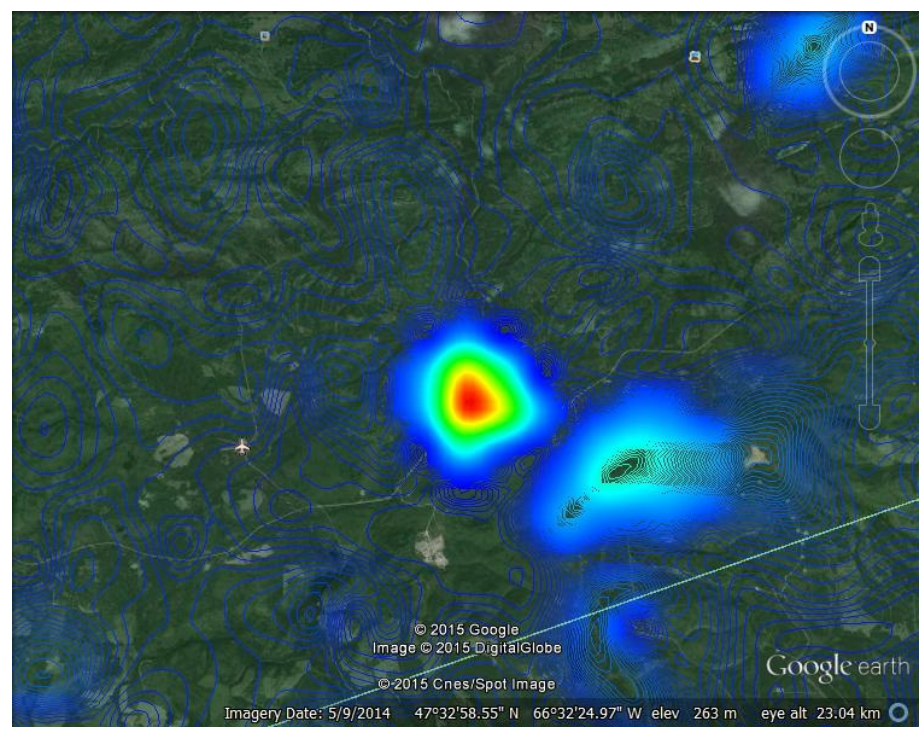

Figure 7: Google Earth mapping of high concentrations of As produced with triangulation interpolation method (Arsenic-Gold formations in Simpsons field). 
The mapping system we developed allows localization of the mines and the concentration of heavy metals in the neighbouring environment (see Figure 7) leading to the better understanding and visualization of the mines activities [7] and potentially of the contamination in the area surrounding the mines or even occurring naturally in the specific geological rock formations [8].

This mapping application provides a new visualization tool and online access to the existing data about the contamination from mining activities that might help people to better understand the problem from different perspective [8].

The database attributes can be used to show the condition and effectiveness of each mine, and to classify them according to their locations, importance and status [8].

Users of this web GIS site are able to extract information, on demand, in realtime, of any mine exploitation and to overlay the geochemical map of the area for comparison. This provides the basis for an easy assessment of the current situation and eventually collecting additional samples for the same area for testing the contamination concentration [8].

The maps showing the mining activities and contaminated areas are helping the people to understand the situation and be more aware of the problem, especially that it can affect the wildlife, plants, animals, fishery, recreation, sensitive areas and cultural resources [8].

\section{Results and conclusions}

We have shown that the mining activities and its proximity and influence to the near-by communities can be presented and documented via online mapping. The data are available from the Canadian web portals and this allows for rapid mapping of environmental impact from mines and tailing ponds. In this research project we have shown that all these data processing and mapping can be automated, enabling general public as well as to decision makers to visualize and understand the risks of the environmental pollution from tailing ponds and mining activities.

\section{References}

[1] Mining - the Canadian encyclopedia. http://www.thecanadianencyclopedia.ca/en/article/mining/. Accessed: $15^{\text {th }}$ April 2015.

[2] Mount Polley mine disaster. http://en.wikipedia.org/wiki/Mount Polleyminedisaster. Accessed: $15^{\text {th }}$ April 2015.

[3] New Brunswick - the Canadian encyclopedia. http://www.thecanadianencyclopedia.ca/en/article/new-brunswick/. Accessed: $15^{\text {th }}$ April 2015.

[4] Tailings pond leaks revealed at Cassidy lake mine site - New Brunswick CBC news.http://www.cbc.ca/news/canada/new-brunswick/tailings-pondleaks-revealed-at-cassidy-lake-mine-site-1.2768759. Accessed: $15^{\text {th }}$ April 2015. 
[5] Aboriginal affairs first nations communities - aboriginal affairs - NB. http://www2.gnb.ca/content/gnb/en/departments/aboriginalaffairs/fnc.html. Accessed: 15th April 2015.

[6] El Niño Ventures Inc. - news releases - exploration update on the Bathurst option jvbase metals project, Bathurst mining camp, New Brunswick. $\mathrm{http} / / / \mathrm{www}$. elninoventures.com/s/NewsReleases.asp?ReportID=553466. Accessed: $15^{\text {th }}$ April 2015.

[7] First nations learn to map territories using Google Earth - Aboriginal - CBC. http://www.cbc.ca/news/aboriginal/first-nations-learn-to-map-territoriesusing-google-earth-1.2746110. Accessed: 15th April 2015.

[8] D. Mioc, F. Anton, A. Ahmad, K. K. Moreiri, B. Nikerson, E. McGillivray, M. Mezouaghi, L. Mofford, and P. Tang. Risk maps for evaluation of natural and man-made hazards. Wit Transactions on Information and Communication Technologies, Wit Trans. Inf. Commun. Tecnol, 44, pp. 141-151, 2012. 